\title{
DRIVERS OF CLIMATE CHANGE ADAPTATION IN ARTISANAL FISHERIES: A CASE OF MALAWI
}

\author{
Yanjanani $K A M B A * 1$ (D), Assa MAGANGA ${ }^{2}$, Sam KATENGEZA ${ }^{l}$
}

\begin{abstract}
Address:
${ }^{1}$ Lilongwe University of Agriculture and Natural Resources, Bunda College of Agriculture, Faculty of Development Studies, Department of Agricultural and Applied Economics, P.O. Box 219, Lilongwe, Malawi

${ }^{2}$ University of Malawi, Chancellor College, Faculty Social Sciences, Department of Economics, P. O. Box 280, Zomba, Malawi

* Corresponding author: yanjananikamba@gmail.com
\end{abstract}

\begin{abstract}
This study was conducted to understand fishers' climate change adaptation decisions in order to move climate informed policy for artisanal fisheries in developing economies forward. Data were collected from a random sample of 220 fishers in Mangochi District in Malawi. A binary probit model and a multivariate probit model were used to assess factors that affect fishers' decision to adapt to climate change and their choice of adaptation strategies respectively. The study found that factors such as sex, education level, fishing experience, household size, fishing income, perception of catch rate trend, social capital and access to extension service corresponded in an increase in the probability of fishers adapting to impacts of climate change by increasing fishing effort, engaging in migratory fishing, investing in improved gear and livelihood diversification. The study recommends strengthening the education system in riparian communities to equip fishers with skills employable outside fishing and at the same time relive pressure off aquatic ecosystems.
\end{abstract}

Keywords: climate change; fisheries; adaptation; probit; Malawi

JEL: C13; D91, Q22, Q54

\section{INTRODUCTION}

A fishery's productivity is closely linked to the functioning and health of its aquatic ecosystem on which it depends for survival. Growth, mortality and reproduction of fish are indirectly affected by changes in their physical environments caused by a change in climate, while feeding, migration and breeding are directly affected by the same (Ogutu-Ohwayo et al., 2016). Due to their poikilothermic nature, fish are very sensitive to their surrounding environment as such, fish always seek an external environment which is in synchrony with their preferred internal environment, a term referred to as behavioural thermoregulation (Cheung et al., 2009; Keefer et al., 2018). This behavioural response has been predicted to contribute to decline in catches in developing economies by about $40 \%$ as it results in migration of fish stock mainly from areas experiencing warming (Cinner $\boldsymbol{e t}$ al., 2009; Cheung et al., 2009; Daw et al., 2012).

The decreases in the availability and quality of fish in warmer areas has caused fishery-dependent communities to face heightened vulnerability resulting in unstable livelihoods. To maintain their livelihood source, fishers implement various adaptation strategies. Adaptation enhances resilience and reduces vulnerability of individuals, communities or activities to climate change (Galappaththia et al., 2018). Research has shown that climate change would not immediately slow down economic growth and that is a window of opportunity for the development of smart and forward looking adaptation policies (Arndt et al., 2014). In spite of that, little is known about the socio-economic environment in which fishers make their decisions with respect to climate change adaptation. This study attempts to fill this gap by assessing the socio-economic, institutional and demographic factors which affect fishers' climate change adaptation decisions.

In modelling determinants of adaptation, binary choice models have been the most widely used models while the mul tinomial logit model has been widely used to model factors that affect choice of adaptation strategies (Pradhan and Leung, 2004; Sanga et al., 2013). The shortcoming of the multinomial logit model is that it assumes Independence of Irrelevant Alternatives (IIA). The problem of IIA can be avoided by using the multinomial probit model which allows different scale parameters across alternatives. However, both the multinomial logit and multinomial probit models are not good fits for adaptation studies because first, a respondent may choose more than one strategy; second, the error terms among strategies may be correlated. Using the multinomial logit or multinomial probit models does not portray the reality faced by decision makers who are most times faced with alternatives which might be adopted simultaneously and/or sequentially as complements or substitutes. This research opted to use a multivariate probit model which allows error terms to be freely correlated (Capellari and Jenkins, 2003; Hassan and Nhemachena, 2008; Pangapanga and Jumbe, 2012; Mulwa et al., 2017; Thoai et al., 2017) 


\section{DATA AND METHODS}

\section{Theoretical Model}

Fishers' climate change adaptation decisions can be analysed on the basis of alternative decision models. Two main elements comprise this decision; the choice set options to be considered, and the objective function criteria for choosing among options. The objective function defines the decision making process which seeks to find an option that yields the best value of the objective function, subject to constraints present. This is governed by the Random Utility Theory (Ben-Akiva and Boccara, 1995).

When predicting choices, human behaviour cannot be approximated by deterministic parameters. Hence it is stated that human behaviour has a probabilistic nature (Ben-Akiva and Boccara, 1995). It is further argued that while a decision maker knows their utility function, the researcher does not know the exact form of that function. In this case, the decision maker, chooses an alternative if utility $(U)$ of that alternative is greater than that of the next, expressed as $U_{i n}>U_{j n} \forall j \neq i$, where $j$ are the different choices from the choice set $C_{n}$ and the decision maker is labelled $n$. Since the researcher does not know all the aspects of the decision maker's utility function, a representative utility function $V_{j n}=V\left(x_{j n}, S_{n}\right)$ is introduced, with $x_{n j} \forall j$ the attributes of the alternatives and $S_{n}$, some attributes of the decision maker. Utility $V$ is dependent on characteristics the researcher cannot know, hence it follows that $V_{j n} \neq U_{j n}$. The utility can be decomposed as $U_{j n}=V_{j n}+\varepsilon_{j n}$, where $\varepsilon_{j n}$ captures the factors that affect utility but are not known to the researcher and therefore are not included in $V_{j n}$. Is simple terms, $\varepsilon_{j n}$ is the difference between $U_{j n}$ and $V_{j n}$ and could be considered an error term. The form of $\varepsilon_{j n}$ is unknown because $\varepsilon_{j n}$ are factors that affect the utility, but are not known by the researcher as such, these terms are treated as random. The probability that the fisher chooses a certain alternative is expressed by the Eq. 1 .

$P\left(i \mid C_{n}\right)=\operatorname{Pr}\left(U_{i n} \geq U_{j n}, \forall j \in C_{n}\right)$

Following Ben-Akiva and Lerman (1985), the most insightful way of expressing the choice probabilities in choice set $C_{n}$ is to reduce them to a binary problem, alternatives $i$ and $j$. The probability that the fisher, $n$, who is the decision maker will select alternative $i$, or $j$ (Eq. 2).

$$
P_{n}(i)=\operatorname{Pr}\left(U_{\text {in }} \geq U_{j n}\right) \text { and } P_{n}(j)=1-P_{n}(i)
$$

Random utility theory can be made operational by first breaking down the aggregate utility into its deterministic and random components, then specify the deterministic component and the random component (Eq. 3 - Eq.4).

$U_{i n}=V_{i n}+\varepsilon_{i n}$

$U_{j n}=V_{j n}+\varepsilon_{j n}$
$V_{i n}$ and $V_{j n}$ are the systematic components they are assumed to be deterministic because it is the part of the utility that can be observed by the researcher. After separating utility into deterministic and random parts, both parts can now be defined. The term $V$ is not only dependent on the underlying attributes, but also on the attributes of the decision maker, it can be defined as $V\left(Z_{\text {in }}, S_{n}\right)$. Because vectors $Z$ and $S$ are combined to describe $V$, a new vector $x_{i n}=h\left(Z_{i n}, S_{n}\right)$ is defined, $h$ being some vector-valued function. The term $V$ can now be re-written as $V_{i n}=V\left(x_{i n}\right)$ and $V_{j n}=V\left(x_{j n}\right)$. A second function which reflects the theory about how the elements in $x$ influence utility and with parameters that can be easily estimated, we choose functions that are linear in parameters. $\beta=\left(\beta_{1}, \beta_{2}, \ldots, \beta_{k}\right)$ is defined as a vector of $K$ unknown parameters (Eq. 5 - Eq.6).

$V_{i n}=\beta_{1} x_{i n 1}+\beta_{2} x_{i n 2}+\cdots+\beta_{K} x_{i n K}$
$V_{j n}=\beta_{1} x_{j n 1}+\beta_{2} x_{j n 2}+\cdots+\beta_{K} x_{j n K}$

Finally, there is a need to specify the disturbances before obtaining an operational binary choice model. It is usually assumed that the mean of the disturbance is zero and their scale is consistent with the scale of the functions $V$. The disturbances can be viewed as being the sum of a large number of unobserved and independent components. Following the law of central limit theorem, the disturbances tend to be normally distributed. It can now be stated that $\varepsilon_{\text {in }}$ and $\varepsilon_{j n}$, both have a normal distribution with mean zero and variances $\sigma_{i}^{2}$ and $\sigma_{j}^{2}$ respectively, and the difference between the disturbances also has a normal distribution with zero mean and variance $\sigma_{i}^{2}+\sigma_{j}^{2}-2 \sigma_{i j}$ $=\sigma^{2}$. When $V_{i n}=\beta^{\prime} x_{i n}$ and $V_{j n}=\beta^{\prime} x_{j n}$, it can be stated for the choice probabilities (Eq.7).

$P_{n}(i)=\Phi\left(\frac{\beta^{\prime}\left(x_{i n}-x_{j n}\right)}{\sigma}\right)$

Where $\Phi$ denotes the standardized cumulative distribution. The choice probability is only reliant on $\sigma$, and not on the variance of either the disturbance or covariance. Further, the choice of $\sigma$ is arbitrary, rescaling $\sigma$ or $\beta$ by any positive constant cannot affect the choice probability. Normally $\sigma=1$ is chosen (Ben-Akiva and Lerman, 1985; Macfadden, 1986).

\section{Empirical Framework \\ Sample Selection Probit Model}

Climate change adaptation is a two-stage process: first, one has to perceive climate as changing; second, deciding the course of action to take in response to the changing climate, as such analysis of data to assess to determinants of adaptation followed a two stage procedure. This is the equivalent of the Heckman sample selection model as it was used by Maddison (2007). In the first probit, the regressand was whether a fisher perceived climate change, taking a value of 1 for yes and 0 otherwise. Then an Inverse Mill's Ratio (IMR), a ratio of the probability density function over the cumulative distribution function of a distribution, was derived which was then included in the second probit as a regressor whose regrassand was 
whether a fisher adapted to impacts of climate change, taking a value of 1 for yes and 0 otherwise. This was done to take care of any potential selection biasness at the first stage of decision making. Heckman's sample selection model is based on the following two latent variable models (Eq.8 - Eq.9).

$y_{j}^{*}=x_{j}^{\prime} \beta+\varepsilon_{j}$

$y_{i}^{*}=x_{i}^{\prime} \beta+\varepsilon_{i}$

Where:

$y_{i}^{*}$ is only observable if $y_{j}^{*}>0$. In this way, the real dependent variable is $y=y_{i}$ if $y_{j}^{*}>0, y$ is a missing value is $y_{j}^{*}<0$.

For each person $i$ we can write the utility difference between adapting and not adapting as a function of observed characteristics, $x_{i}$ and unobserved characteristics, $\varepsilon_{i}$. In this case, for a fisher to adapt they first have to perceive the impacts of climate change and the utility of adaptation should exceed a certain threshold, usually set at 0 . Adaptation, $y_{i}=1$ is observed if and only if $y_{i}^{*}>0$ and $y_{i}=0$ (no adaptation) otherwise, expressed as the Eq. 10 .

$y_{i}^{*}=\left\{\begin{array}{l}y_{i}=1 \text { if } y_{i}^{*}>0 \\ y_{i}=0 \text { if } y_{i}^{*} \leq 0\end{array}\right.$

\section{Multivariate Probit Model}

A multivariate probit model was used to determine factors that affect specific choice of adaptation strategies. The model is a multi-response variable model which specified the relationship between choosing adaptation options and a set of independent variables (Ben-Akiva and Bolduc, 1996; Greene, 2005). The model's latent variables are expressed as discrete variables through a threshold specification. The structural form of the model is as the Eq. 11.

$y_{i m}^{*}=\beta_{m}^{\prime} x_{i m}+\varepsilon_{i m}, m=1, \ldots, M$
Where:

$y_{i m}$ is a vector of adaptation strategies, $\beta_{m}^{\prime}$ is a vector of parameters and $x_{i m}$ is a vector of explanatory variables. $\varepsilon_{m}, m=1, \ldots, M$ are error terms distributed as multivariate normal, each with a mean of zero, and variance-covariance matrix, with values of 1 on the leading diagonal and correlations $\rho_{1 m}=\rho_{m 1}$ as offdiagonal elements.

The structural form of the model allows more than one equation with correlated disturbances. The dependent variable represents adaptation strategies. The model is estimated through maximum likelihood using the Geweke-Hajivassiliou-Keane (GHK) smooth recursive conditioning simulator (Geweke, 1996; Chib and Greenberg, 1998; Cappellari and Jenkins, 2003).

\section{Data Sources}

Primary data was collected through a cross section survey of small scale/artisanal fishers in Mangochi district, Malawi. Mangochi is a district located in the southern region of Malawi. Mangochi district has a coverage of 6, $273 \mathrm{~km}^{2}$. It is located at the southern end part of Lake Malawi and $8 \mathrm{~km}$ south of Lake Malombe which is also in the district. It has an average annual temperature of 29.9 ${ }^{\circ} \mathrm{C}$, and an average daily temperature of $24.1^{\circ} \mathrm{C}$ and an average annual precipitation of $846 \mathrm{~mm}$.

\section{RESULTS AND DISCUSSION}

\section{Descriptive Statistics}

Table 1 presents summary statistics of key variables. The average number of years spent schooling was six. This implies that most of the respondents did not finish primary school. It was expected that the probability of adaptation would be higher among highly educated fishers. The addition labour force associated with being married was expected to increase the probability of a fisher adapting to the impacts of climate change. Fishing experience and age were expected to increase the probability of adaptation as more experienced fishers may easily notice changes in climatic patterns than their counterparts.

Table 1 Summary Statistics of Key Variables

\begin{tabular}{llrr}
\hline Variable & Observations & Mean & Std. Dev. \\
\hline Fishing location (1=lake Malawi) & 220 & 0.86 & 0.34 \\
Sex of respondent (1=male) & 220 & 0.98 & 0.12 \\
Age of respondent (years) & 220 & 42 & 10 \\
Education level (years) & 220 & 6.0 & 4.1 \\
Marital status (1=married) & 220 & 0.095 & 0.21 \\
Access to land (1=yes) & 220 & 0.78 & 0.41 \\
Fishing experience (years) & 220 & 12 & 7.4 \\
Household size (number) & 220 & 6.0 & 2.2 \\
Total income (MK) & 220 & $178,306.8$ & $139,886.2$ \\
Fishing income (MK) & 220 & $123,113.6$ & $105,719.8$ \\
Catch rate (Kg per day) & 220 & 128.0 & 100 \\
Social Capital (1=Yes) & 220 & 0.47 & 0.5 \\
Access to credit (1=Yes) & 220 & 0.38 & 0.03 \\
Contacts with extension agent (1=Yes) & 220 & 0.25 & 13.9 \\
\hline
\end{tabular}


Table 2 Perceived trends of some climate variables

\begin{tabular}{llrr}
\hline Climate Variable & Perceptions & Count & Percent \\
\hline Temperature & Increasing & 191 & 87 \\
& Decreasing & 5 & 2.1 \\
& No change & 24 & 10.9 \\
& Total & 220 & 100 \\
\hline Rainfall & Increasing & 18 & 8.4 \\
& Decreasing & 200 & 90.9 \\
& No change & 2 & 0.7 \\
& Total & 220 & 100 \\
\hline Wind Speed & Increasing & 213 & 97 \\
& Decreasing & 0 & 0 \\
& No change & 7 & 3 \\
& Total & 220 & 100 \\
\hline Wind direction & Predictable & 0 & 0 \\
& Unpredictable & 220 & 100 \\
& Total & 220 & 100 \\
\hline
\end{tabular}

The effect of having access to land for farming was expected to vary. Income was expected to be positively associated with adaptation since it requires financial resources. It was expected that fishers with access to credit could use that opportunity as a means of enhancing their adaptive capacity, this was also expected to be true for both social capital and access to extension services.

\section{Adaptation Strategies}

Fishermen who perceived climate change (92\%) were asked to mention how they perceived it. As Table 2 shows, over $90 \%$ percent of the respondents mentioned noticing changes in temperatures, rainfall, and wind patterns.

Naturally, not everyone who perceives climate as changing takes measures to reduce vulnerability and enhance resilience to its impacts. This was also true for this study as of $92 \%$ of the respondents who perceived climate as changing, only $66 \%$ had had taken measures to lessen the negative impacts of climate change on their fishing livelihoods. The $34 \%$ who failed to adapt accounted it to shortage of income, labour, and negligence.

Literature revealed a number of adaptation strategies employed by fishers elsewhere. Respondents of this study however employed the following four non-mutually exclusive adaptation strategies: first, increasing fishing effort. We considered nominal fishing effort as it is readily observable and easily measurable. It describes the resources allocated to fishing such as number of vessel days, gear (net size), time (days or hours), and labour (number of crew) (McCluskey and Lewison, 2008). This strategy was employed by $54 \%$ of the respondents. Second, migratory fishing. We consider internal migration which involves moving of a fisher from one beach to another within the same locality in response to declining catch rate (Kennedy and Raj 2014). This strategy was employed by $52 \%$ of the respondents. Third, investing in improved gear. This involves investing in vessel stability to withstand the harsh conditions associated with climate change. This strategy was employed by $37 \%$ of the respondents. Fourth, livelihood diversification. Livelihood diversification is achieved when households engage in more than one income generating activity to spread risk and decrease vulnerability (Saha and Bahal, 2015). It was employed by $19 \%$ of the respondents.

Respondents of this study employed more than one strategy at any point in time. Of the fishers (41\%) who increased their fishing effort and engaged in migratory fishing simultaneously, $32 \%$ also diversified their livelihood portfolio, and $14 \%$ also invested in improved gear. We went a step further to assess correlations between the four strategies. We found a complementary relationship between increasing fishing effort and migratory fishing, significant at $p<0.01$; livelihood diversification and migratory fishing, significant at $p<$ 0.01 ; livelihood diversification and investing in improved gear, significant at $p<0.05$.

\section{Factors Affecting Adaptation to Climate Change}

In Table 3 we present estimates of the binary probit model on factors affecting fishers' adaptation to climate change. The data were tested for multicollinearity using Variance Inflation Factors (VIF) through the 'collin' of the Stata package and there was no evidence of worrisome collinearity. Robust standard errors were used to take care of any heteroskedasticity in the model. The IMR was not significant meaning that there was no proof of selection biasness in the data which appropriated the use of the standard binary probit model. Discussion of the results is based on marginal effects which provide a meaningful way of quantifying changes in the dependent variable due to changes in independent variables. For dummy variables, the marginal effects represent discrete change of dummy from 0 to 1 . Interpretation of the marginal effects assumes a ceteris paribus condition for the other independent variables.

The model was robust and overall significant $\left(\right.$ Prob $\left.>\chi^{2}=0.0000\right)$. The results in Table 3 show that the probability of adaptation was higher for male fishers than for their female counterparts. A marginal effect of 0.1960 implies that being a male fisher significantly ( $p<$ 0.1 ) increases the probability of adapting to the impacts of climate change by 19.6 percentage points. This result was expected as women's access to resources that would enable them to adapt to climate change in the same way as men may not be the same as men's.

Education had a significant $(p<0.01)$ relationship with adaptation. A marginal effect of 0.0164 sugges ts that a unit increase in a fisher's education increases their probability of adapting to the impacts of climate change by 1.64 percentage points. Being educated is associated with openness to change and an easy understanding of complex concepts such as climate change as such it enhances the ability of a fisher to make informed decisions based on available information.

With a marginal effect of 0.10 , having access to land had a negative significant $(p<0.05)$ effect on fishers' adaptation decisions. Having access to land decreased the probability of a fisher adapting to the impacts of climate change by 10 percentage points. This could be because farming is an alternative source of income such that those with more land are more likely to invest in farming than adapt their fishing practices to the impacts of climate 
change, more especially when fishing is not the main income source.

Fishing experience was positive and significant $(p<$ 0.01). A marginal effect of 0.016 suggests that a unit increase in fishing experience increased the probability of the fisher adapting to the effects of climate change by 1.6 percentage points. Highly experienced fishers can easily notice changes in climatic conditions. They become acquainted with weather forecasting which enables them to easily adjust themselves to actual and anticipated changes. This result agrees with Maddison (2007) and Hassan and Nhemachena et al. (2008) on their climate change adaptation studies in crop production for farmers in southern Africa.

Household size was positive and significant $(p<$ $0.05)$. An increase in household size by one member corresponded to an increase in the probability of a fisher adapting to the impacts of climate change by 2 percentage points. The possible reason could be that larger household sizes are associated with a higher labour endow ment. This is more likely to enable them to carry out various labour demanding adaptation activities more than their counterparts (Bryan et al., 2009). However, Hassan and Nhamachena (2008) reported that household size has mixed impacts in spite of their finding that it increased adaptive capacity of farmers. They explained that some households with larger sizes tend to divert their members to source income from other activities and hence reducing labour allocated to the main source of income and hence making adaption less likely.

A 10 percent increase in fishing income was significantly $(p<0.01)$ associated with an increase in the probability of a fisher adapting to the impacts of climate change by 1.66 percentage points. This might be because adaptation requires financial resources hence an increase in income obtained from fishing acts as an incentive for further investments in the same.
Membership to a social group was used as a proxy for social capital. This refers to formal or informal social networks in which members of a household are engaged to secure their livelihood. Social capital significantly ( $p<$ 0.01 ) increased the probability of a fisher adapting to the impacts of climate change by 13 percentage points. This could be because such groups act as a platform for exchange of information and other resources which could then enhance adaptation.

A unit increase in the number of extension visits by an extension worker significantly $(p<0.01)$ corresponded to an increase in the probability of a fisher adapting to impacts of climate change by 0.9 percentage points. Fishers with more extension visits are better informed about the consequences of climate change and possible actions that could be taken (Deressa et al., 2008; Hassan and Nhemachena, 2008; Khanal et al., 2018).

\section{Factors Affecting Choice of Adaptation Strategies}

We estimated a multivariate probit model to examine factors influencing choice of adaptation strategies. The results are presented in Table 4.

The model was robust and overall, significant $\left(\right.$ Prob $\left.>\chi^{2}=0.0000\right)$. The model had a log likelihood ratio of -361.047 with 30 draws per observation. Robust standard errors were used to account for any heteroscedasticity in the data. The hypothesis that the correlations between the error terms in the adaptation strategies equations were equal to zero was rejected ( Prob $\left.>\chi^{2}=0.000\right)$ implying that there was endogeneity within the data and multivariate probit was the right model to use. This endogeneity was corrected using the Geweke-Hajivassiliou-Keane (GHK) smooth recursive conditioning simulator, a simulation method for evaluating multivariate normal distribution functions (Capellari and Jenkins, 2003).

Table 3 Binary Probit Model Estimates

\begin{tabular}{|c|c|c|c|}
\hline Variable & Marginal effects & Robust Std. Err. & Z-statistic \\
\hline Fishing location (1=lake Malawi) & -0.003 & 0.056 & -0.05 \\
\hline Sex of respondent ( $1=$ male $)$ & 0.196 & 0.109 & $1.79 *$ \\
\hline Marital status ( $1=$ married $)$ & -0.024 & 0.082 & -0.29 \\
\hline Age of respondent (years) & -0.002 & 0.002 & -0.75 \\
\hline Education level (years) & 0.016 & 0.005 & $3.06 * * *$ \\
\hline Access to land (1=yes) & -0.101 & 0.047 & $-2.15 * *$ \\
\hline Fishing experience (years) & 0.017 & 0.004 & $3.78 * * *$ \\
\hline Household size (number) & 0.021 & 0.011 & $1.96 * *$ \\
\hline Log of total income (MK) & -0.088 & 0.056 & -1.58 \\
\hline Log of fishing income(MK) & 0.166 & 0.059 & $2.8 * * *$ \\
\hline Catch rate $(\mathrm{Kg})$ & 0.000 & 0.000 & -1.63 \\
\hline Social Capital (1=yes) & 0.132 & 0.041 & $3.22 * * *$ \\
\hline Access to credit (1=yes) & -0.013 & 0.039 & -0.34 \\
\hline Contacts with extension agents (contacts/Year) & 0.009 & 0.002 & $5.09 * * *$ \\
\hline Number of obs & 220 & & \\
\hline Pseudo $\mathrm{R}^{2}$ & 0.5989 & & \\
\hline $\operatorname{LR} \chi^{2}(15)$ & 86.30 & & \\
\hline Prob $>\chi^{2}$ & 0.0000 & & \\
\hline Pearson $\chi^{2}(192)$ & 423.66 & & \\
\hline Prob $>\chi^{2}$ & 0.0000 & & \\
\hline
\end{tabular}


Table 4: Multivariate Probit Model Estimates

\begin{tabular}{|c|c|c|c|c|}
\hline Variables & $\begin{array}{l}\text { Increasing fishing } \\
\text { effort } \\
\text { dy/dx } \\
\text { (Std. Err.) }\end{array}$ & $\begin{array}{l}\text { Migration of fishing } \\
\text { efforts } \\
\text { dy/dx } \\
\text { (Std. Err.) }\end{array}$ & $\begin{array}{l}\text { Investing in improved } \\
\text { gear } \\
\text { dy/dx } \\
\text { (Std. Err.) }\end{array}$ & $\begin{array}{l}\text { Livelihood } \\
\text { diversification } \\
\text { dy/dx } \\
\text { (Std. Err.) }\end{array}$ \\
\hline Fishing location (1=lake Malawi) & $-0.146(0.091)$ & $-0.042(0.089)$ & $0.160(0.099)$ & - \\
\hline Sex of respondent $(1=$ male $)$ & $0.142(0.222)$ & $-0.045(0.172)$ & $-0.052(0.246)$ & - \\
\hline Marital status (1=yes) & $-0.051(0.133)$ & $-0.110(0.104)$ & $0.153(0.160)$ & $-0.078(0.067)$ \\
\hline Age of respondent (years) & $-0.002(0.003)$ & $-0.006(0.003)^{* *}$ & $-0.001(0.003)$ & $0.000(0.002)$ \\
\hline Education level (years) & $0.021(0.008)^{* * *}$ & $0.020(0.007)^{* * *}$ & $0.010(0.007)^{* * *}$ & $0.020(0.006)^{* * *}$ \\
\hline Access to land (1=yes) & $-0.185(0.066)^{* * *}$ & $-0.099(0.067)$ & $-0.049(0.068)$ & $0.167(0.058)^{* * *}$ \\
\hline Fishing experience (years) & $0.022(0.005)^{* * *}$ & $0.029(0.004)^{* * *}$ & $0.021(0.004)^{* * *}$ & $0.007(0.003)^{*}$ \\
\hline Household size (number) & $0.039(0.012)^{* * *}$ & $0.009(0.012)$ & $0.000(0.016)$ & $0.009(0.009)$ \\
\hline Log of total income (MK) & $-0.121(0.094)$ & $-0.242(0.073)^{* * *}$ & $0.092(0.074)$ & $-0.003(0.056)$ \\
\hline Log of fishing income (MK) & $0.200(0.087)^{* *}$ & $0.243(0.072)^{* * *}$ & $0.066(0.081)$ & $-0.016(0.062)$ \\
\hline Catch rate $(\mathrm{Kg})$ & $-0.0001(0.0004)$ & $-0.000(0.000)$ & $-0.000(0.000)$ & $-0.000(0.000)$ \\
\hline Social capital (1=yes) & $0.196(0.061)^{* * *}$ & $0.124(0.058)^{* *}$ & $0.077(0.061)$ & $0.111(0.050)^{* *}$ \\
\hline Access to credit (1=yes) & $0.028(0.067)$ & $0.041(0.060)$ & $-0.000(0.062)$ & $-0.051(0.052)$ \\
\hline $\begin{array}{l}\text { Access to extension services } \\
\text { (Contacts/year) }\end{array}$ & $0.006(0.002)^{* * *}$ & $0.010(0.002)^{* * *}$ & $0.005(0.002)^{* *}$ & $0.011(0.002)^{* * *}$ \\
\hline Number of obs & 220 & & & \\
\hline Wald $\chi^{2}(60)$ & 265.23 & & & \\
\hline Prob $>\chi^{2}$ & 0.0000 & & & \\
\hline Log likelihood & -361.047 & & & \\
\hline
\end{tabular}

\section{Factors that affect increasing fishing effort}

We found positive and significant correlations between increasing fishing effort strategy, and education level of the fisher, fishing experience, household size, fishing income, social capital and access to extension. On the other hand, we found negative correlations between fishing effort and land access.

A unit increase 1 in the number of years spent in school corresponded to an increase in the probability of a fisher increasing his or her fishing effort as a response to the effects of climate change by 2.1 percentage points, significantly at $p<0.01$.

Having access to land, significantly $(p<0.01)$ decreased the probability of a fisher to increase his or her fishing efforts in response to climate change by 18.5 percentage points. This could be because farming and fishing both compete for the same human and financial resources within a fisher's decision unit. For this reason, those who have access to land and engage in farming could increase their effort in such activities than in fishing.

A unit increase in fishing experience increased the probability of fishers adapting to impacts of climate change by increasing their fishing effort by 2.2 percentage points.

A unit increase in household size significantly $(p<$ 0.01 ) increased the probability of that household unit increasing its fishing effort as a climate change adaptation measure by 3.9 percentage points. This could be because more household members translate into a higher labour endowment, enough to accommodate the labour demanding nature of this adaptation option.

The relationship between log of fishing income and fishing effort suggests that a 10 percent increase in fishing income increases the probability of a fisher adapting to impacts of climate change by increasing fishing effort by
2 percentage points, significant at $p<0.05$. Increasing fishing effort is subject to increasing costs hence increased income helps fishers to meet transaction costs which are associated with increasing fishing effort (Anderson, 1988; McClusky and Lewison, 2008; Khanal, 2018).

Having social capital, significantly $(p<0.01)$ increased the probability of increasing fishing effort in response to climate change by 19.6 percentage points. This is consistent with our priori expectation since social capital lubricates transaction costs, facilitates learning and the associated peer influence could translate into cheap labour for a fisher to hire crew men, even net mending or boat construction. Social capital could also facilitate non-cash transactions between members.

Increasing access to extension by one unit significantly $(p<0.01)$ contributed to fishers increasing their fishing effort in response to climate change by 0.6 percentage points. We suspect that the messages which extension agents provide to fishers help them make comparative decisions among competing adaptation alternatives according to their different situations.

\section{Factors that affect migratory fishing}

We found positive and significant relationships between migratory fishing and education level, fishing experience, fishing income, social capital and access to extension. We found significant and negative relationships between migratory fishing, age, and total income.

A unit increase in the age of a fisher decreased the likelihood of that fisher engaging in seasonal migration by 0.6 percentage points, significant at $p<0.05$. It could be explained by the fact that migratory fishing might be too demanding for older fishers. This also agrees with Kennedy and Raj (2014).

A unit increase in education corresponded to an 
increase in the probability of a fisher engaging in migratory fishing in response to climate change by 2 percentage points, significant at $p<0.01$.

A unit increase in fishing experience significantly $(p<0.01)$ increased the probability of a fisher engaging in migratory fishing in response to impacts of climate change by 2.9 percentage points. More experienced fishers are more likely to know when and where efforts are productive with respect to specific climatic conditions.

A 10 percent increase in total income decreased the probability of a fisher engaging in migratory fishing in response to impacts of climate change by 2.42 percentage points, significant at $p<0.1$. As Jul-Larsen et al. (2003) explained, wealthier fishers combine a number of sources of income, this could reduce their time on fishing if it is declining and hence reduce chances of seasonal migration. However, a 10 percent increase in fishing income suggested a significant $(p<0.01)$ increase in the probability of a fisher engaging in migratory fishing in response to the impacts of climate change by 2.43 percentage points. This is consistent with findings by Kennedy and Raj (2014) who reported that an increase in fishing income increased the probability of migration for fishers. Allison et al. (2007) also reported that rich fishers whose main source of income was fishing, migrated to Lake Malawi and Malombe from Lake Chilwa during the Lakes dry out periods in the past.

Having social capital, significantly $(p<0.01)$ contributed to a fisher engaging in migratory fishing in response to impacts of climate change by 12.4 percentage points and a unit increase in contacts with an extension agent significantly $(p<0.01)$ increased the probability of a fisher engaging in migratory fishing by 1 percentage point.

\section{Factors that affect investment in improved fishing gear}

We found positive and significant relationships between investing in improved gear and education level, fishing experience, and access to extension. The relationship between education level and investments in improved fishing gear was positive and significant $(p<0.01)$. A unit increase in the education of a fisher increased the probability of that fisher adapting to the impacts of climate change by investing in improved fishing gear by 1 percentage point.

A unit increase in fishing experience significantly $(p<0.01)$ increased the probability of a fisher investing in improved fishing gear in response to climate change by 2.1 percentage points.

Access to extension was significant at $p<0.05$. A unit increase in extension service increased the probability of a fisher investing in improved fishing gear in response to climate change by 0.5 percentage points.

\section{Factors that affect livelihood diversification}

We found positive and significant relationships between livelihood diversification and education level, fishing experience, access to land, social capital, and access to extension.

A unit increase in a fisher's education level significantly $(p<0.01)$ increased the probability of a fisher diversifying their livelihood sources in response to impacts of climate change by 2 percentage points. Higher education generally builds human capital and contribute to improved skills in an individual. Uneducated fishers are unable to weave skills that could help them tap into other resources. These are obstructed from accessing alternative livelihood niches especially in the non-fishing sector (Kassie et al., 2017).

Having access to land for farming, significantly ( $p<$ 0.01 ) increased the probability of a fisher diversifying their livelihood sources, by 16.7 percentage points. In response to impacts of climate change, fishers with land might diversify their source of income by engaging more in commercial farming (Saha and Bahal, 2015; Kassie $\boldsymbol{e t}$ al., 2017; Edet and Etim, 2018).

The relationship between fishing experience and livelihood diversification was positive and significant $(p<0.1)$. A unit increase in fishing experience increased the probability of a fisher diversifying their livelihood portfolio by 0.7 percentage points. This implies that fishers with more fishing experience were more likely to engage in livelihood diversification than their counterparts. It can be explained by the notion that having more experience relates to acquisition of skills which can be applied in other income generating activities like boat repairing.

Having social capital, significantly $(p<0.05)$ increased the probability of a fisher diversifying their livelihood sources, by 11.1 percentage points. As Kassie et al. (2017) also reported, individuals who come together in promotion of mutual interests could help each other perceive and capitalise on livelihood alternatives.

Access to extension, significant at $p<0.01$, also contributed to livelihood diversification among fishers. A unit increase in visits by an extension agent increased the probability of a fisher diversifying their livelihood sources in response to impacts of climate change by 1.1 percentage points. It could be because extension agents act as a source of information on how livelihood diversification spreads risk and how it is a pathway to poverty reduction.

\section{CONCLUSIONS}

The study revealed that most fishers are aware of climate change but not all take action to lessen its adverse impacts on their fishing practices. The study revealed the following four private adaptation strategies that fishers employ: increasing fishing effort; migratory fishing; investing in improved gear; and livelihood diversification. Adaptation and choice of adaptation strategies were affected by factors such as sex, education level, fishing experience, household size, fishing income, social capital and access to extension service are positively associated with adaptation while access to land is negatively associated with fishers' adaptation to the effects of climate change.

The study recommends improving the adaptive capacity of fishers by increasing awareness of climate change among fishermen. This can be achieved by strengthening both formal and informal extension services; and by strengthening the education system in riparian communities and equipping them with vocational 
skills which they could weave to tap into other resources for income which would consequently relive pressure off the aquatic ecosystem and hence prevent overfishing.

Acknowledgements: Many thanks to the African Centre of Excellence in Aquaculture and Fisheries (AQUAFISH) and the Africa Economic Research Consortium (AERC) for the financial support which made this research possible.

\section{REFERENCES}

ALLISON, E. H., ANDREW, N. L., \& Oliver, J. (2007). Enhancing the Resilience of Inland Fisheries and Aquaculture Systems to Climate Change. Journal of SAT Agricultural Research, 4(1), p. 1-35. https://hdl.handle.net/20.500.12348/1593

ARNDT, C., SCHLOSSER, A., STRZEPEK, K., \& THURLOW, J. (2014). Climate Change and Economic Growth Prospects for Malawi: An Uncertainty Approach. Journal of African Economies, 23(2), p. ii83-ii107. DOI: $\underline{10.1093 / \text { jae/eju013 }}$

BEN-AKIVA, M.E., \& BOCCARA, B. (1995). Discrete choice models with latent choice. International Journal of Research in Marketing 19, p. 9-24. DOI: 10.1016/01678116(95)00002-J

BRYAN, E., DERESSA, T. T., GBETIBOUO, G. A., \& RINGLER, C. (2009). Adaptation to Climate Change in Ethiopia and South Africa: Options and Constraints. Environmental Science and Policy, 12(4), p. 413-426. DOI: $10.1016 /$ j.envsci.2008.11.002

CAPELLARI, L., \& JENKINS, S. P. (2003). Multivariate Probit Regression Using Simulated Maximum Likelihood. The Stata Journal, 3(3), p. 278-294. DOI: https://doi.org/10.1177/1536867X0300300305

CINNER, J. E., DAW, T., and McCLANAHAN, T. R. (2009). Socioeconomic Factors that Affect Artisanal Fishers' Readiness to Exit a Declining Fishery. Conservation Biology, 1, p. 30-124. DOI: https://doi.org/10.1111/j.1523-1739.2008.01041.x

CHEUNG,W.W. L., LAM, V.W. Y., SARMIENTO, J. L., KEARNEY, K.,WATSON, R., \& PAULY, D. (2009). Projecting global marine biodiversity impacts under climate change scenarios. Fish and Fisheries 10, 235-251. DOI: https://doi.org/10.1111/j.1467-2979.2008.00315.x CHIB, S., \& GREENBERG, E. (1998). Analysis of Multivariate Probit Models. Biometrika, 85(2): 347-367. DOI: $\underline{10.1371 / \text { journal.pone. } 0031460}$

DAW, T. M., CINNER, J. E., MCCLANAHAN, T. R., BROWN, K., STEAD, S. M., GRAHAM, N. A., \& MAINA, J. (2012). To Fish or ot to Fish: Factors at Multiple Scales Affecting Artisanal Fishers' Readiness to Exit a Declining Fishery. PLoS ONE, 7(2), p. 1-10. DOI: https://doi.org/10.1371/journal.pone.0172075

DERESSA, T., HASSAN, R., ALEMU, T., YESUF, M., \& RINGLER, C. (2008). Analyzing the Determinants of Farmers' Choice of Adaptation Methods and Perceptions of Climate Change in the Nile Basin of Ethiopia. Discussion Paper, IFPRI.

EDET, G. E., \& ETIM, N. A. A. (2018). Factors Influencing Rural Livelihood Diversification: Implications for Poverty Reduction. International Journal of Agriculture, Forestry and Fisheries, 6(2), p. 23-28. GALAPPATHTHIA, E.K., FORD, J.D., \& BENNETT, E.M. (2018). A framework for assessing community adaptation to climate change in a fisheries context. Environmental Science and Policy, 92, p. 17-26. DOI: doi.org/10.1016/j.envsci.2018.11.005

GEWEKE, J. (1996). Monte Carlo Simulation and Numerical Integration. In Handbook of Computational Economics, 1, p. 731-800. DOI: https://doi.org/10.1016/S1574-0021(96)01017-9

HASSAN, R., \& NHEMACHENA, C. (2008). Determinants of African Farmers' Strategies for Adapting to Climate Change: Multinomial Choice Analysis. African Journal of Agricultural and Resource Economics, 2(1), p. 83-104. DOI: 10.22004/ag.econ.56969

JUL-LARSEN, E., KOLDING, J., NIELSEN, J. R., \& VAN ZWIETEN, P. A. (2003). Management, CoManagement or No Management? Major Dilemmas in Sourthern African Freshwater Fisheries. Rome: FAO fisheries Technical paper 426/1.

KASSIE, G. W., KIM, S., \& FELLIZAR, F. P. (2017). Determinant Factors of Livelihood Diversification: Evidence from Pretoria. Cogent Social Sciences, 3 (1), p. 1-16. DOI: 10.1080/23311886.2017.1369490

KEEFER, M. L., CLABOUGH, T. S., JEPSON, M. A., BOWERMAN, T., \& CAUDILL, C. C. (2018). Temperature and depth profiles of Chinook salmon and the energetic costs of their long-distance homing migrations. Journal of Thermal Biology 79, p. 155-165. DOI: 10.1016/j.jtherbio.2018.12.011

KENNEDY, D. J., \& RAJ, S. P. (2014). Determinants of Fishermen Migration: Study on a Traditional Marine Fishing Village in Kanyakumari District. International Journal of Research in Management, Social Sciences and Technology, 8(8), p. 1-8.

KHANAL, U., WILSON, C., HOANG, V. N., \& LEE, B. (2018). Farmers' Adaptation to Climate Change, Its Determinants and Impacts on Rice Yield in Nepal. Ecological Economics 144, p. 139-147. DOI: 10.1016/j.ecolecon.2017.08.006

MADDISON, D. (2007). The Perception of and Adaptation to Climate Change in Africa. Policy Research Working Paper No. 4308. Washington DC: World Bank. DOI: https://doi.org/10.1596/1813-9450-4308

McCLUSKEY, S. M., \& LEWISON, R. L. (2008). Quantifying Fishing Effort: a Synthesis of Current Methods and their Applications. Fish and Fisheries, 9, p. 188-200. DOI: 10.1111/j.1467-2979.2008.00283.X

MULWA, C., MARENYA, P., RAHUT, D.B., \& KASSIE, M. (2017). Response to climate risks among smallholder farmers in Malawi: A multivariate probit assessment of the role of information, household demographics, and farm characteristics. Climate Risk Management 16, p. 208-221. DOI: 10.1016/j.crm.2017.01.002

OGUTU-OHWAYO, R., NATUGONZA, V., MUSINGUZI, L., OLOKOTUM, M., \& NAIGAGA. (2016). Implications of climate variability and change for African lake ecosystems, fisheries productivity, and livelihoods. Journal of Great Lakes Research 42(3), p. 498-510. DOI: 10.1016/j.jglr.2016.03.004

PANGAPANGA, I. P., JUMBE, C., KANYADA, S., \& 
THANGALIMODZI, L. (2012). Unravelling Strategic Choices towards Droughts and Floods Adaptation in Southern Malawi. International Journal of Disaster Risk Reduction, 2, p. 57-66. DOI: 10.1016/j.ijdrr.2012.08.002 PRADHAN, N. C., \& LEUNG, P. (2004). Modeling Entry, Stay, and Exit Decisions of the Longline Fishers in Hawaii. Marine Policy, 28, p. 311-324. DOI: 10.1016/j.marpol.2003.09.005

SAHA, B., \& BAHAL, R. (2015). Factors Leading to Success in Diversified Occupation: A Livelihood Analysis in India. The Journal of Agricultural Education and Extension, 21(3), p. 249-266. DOI: 10.1080/1389224X.2014.927372
THOAI T. Q, RANOLA R. F, CAMACO L. D., \& SILMETON E, 2017. Determinants of farmers' adaptation to climate change in agricultural production in the central region of Vietnam. Land Use Policy 70, p. 224-231. DOI: $\underline{10.1016 / j . l a n d u s e p o l .2017 .10 .023}$ 